\title{
Gestão Cooperativa, Ambiente Institucional e Sociocultural: o caso Brasil-Paraguaii ${ }^{1}$
}

\author{
Marcelo Resquetti Tarifa² e Erneldo Schallenberger ${ }^{3}$
}

Resumo: O objetivo deste estudo foi analisar as influências do ambiente institucional e sociocultural na gestão cooperativista da C. Vale - Cooperativa Agroindustrial comparativamente às unidades brasileiras paranaenses mais representativas e as unidades sediadas no Paraguai. As análises do ambiente institucional tomaram como base a Nova Economia Institucional com ênfase na teoria de Douglass North (1990) sobre as instituições e ocorreram com entrevistas in loco a cada unidade cooperativa contemplada pela amostra. As análises do ambiente cultural pautaram-se na caracterização da cultura organizacional de cada unidade cooperativa, conforme o Competing Value Model desenvolvido por Cameron e Quinn (1998). As análises do ambiente social se embasaram no conceito teórico de capital social e nas respectivas características identificadas nas unidades, por meio da adaptação do modelo proposto pelo grupo de estudos do Banco Mundial (BM), elaborado por Grootaert et al. (2003), via análises de conteúdo e das entrevistas realizadas. Como resultado à problemática estabelecida, concluiu-se que, mesmo a C. Vale sendo uma única cooperativa, há influências do ambiente institucional e sociocultural no processo de gestão nas unidades cooperativas paranaenses e paraguaias. Por fim, conforme a proposta de agrupamento das unidades cooperativas com base nos dados coletados, foram identificados quatro clusters específicos.

Palavras-chaves: Cooperativismo agroindustrial; Teoria institucional; Cultura organizacional; Capital social.

\footnotetext{
Abstract: The purpose of this paper was to analyze the influence of institutional and socio-cultural environment in the cooperative management of the C. Vale-Agroindustrial Cooperative, compared to the most representative units located in Parana, Brazil, and the ones located in Paraguay. The analyses of the institutional environment were based on the New Institutional Economics, with emphasis on the Douglass North's theory (1990)

1. Data de submissão: 30 de junho de 2015. Data de aceite: 30 de junho de 2016.

2. Universidade Estadual de Londrina (UEL). Londrina, Paraná, Brasil. E-mail: marcelotarifa@hotmail.com

3. Universidade Estadual do Oeste do Paraná (Unioeste). Toledo, Paraná, Brasil. E-mail: erneldo@uol.com.br
} 
about the institutions and occurred with in loco interviews in each cooperative unit that was covered by the sample. The analysis of the cultural environment was based on the characterization of the organizational culture of each cooperative unit, according to the Competing Value Model, developed by Cameron and Quinn (1998), that typifies it in group culture, innovative, market and hierarchical, applied to the same managers, through online electronic questionnaire. The analysis of the social environment was based on the theoretical concept of social capital and the respective characteristics identified in the units by adapting the model proposed by the World Bank study group (BM), prepared by Grootaert et al. (2003), through the content analysis of the interviews. As a result to the established problem it was concluded that, even C.Vale being a single cooperative, there are influences of the institutional and the socio-cultural environment in the process of management of the cooperative units in Paraná and Paraguay. Finally, according to the grouping proposal of the cooperative units based on the collected data, four specific clusters were identified.

Key-words: Agroindustrial cooperativism; Institutional theory; Organizational culture; Social capital.

DOI - http://dx.doi.org/10.1590/1234-56781806-94790540402

Classificação JEL: Q1, Q13.

\section{Introdução}

A partir das mudanças históricas ocorridas no contexto social, cultural e econômico, o cooperativismo destacou-se no cenário internacional como uma opção de gestão, baseada na obtenção dos objetivos pessoais por meio da coletividade e da solidariedade que se fortaleceu pelos seus princípios originais. Além da discussão voltada aos sete princípios originais (ICA, 2013), o cooperativismo deve ser pesquisado como um modo de gestão que sofreu notórias transformações ao longo dos anos, o que pode ter impactado diretamente as regiões contempladas por tais formas de organização e ter influenciado diretamente a gestão cooperativa. Nas mais diversificadas regiões brasileiras, um dos ramos de cooperação de maior destaque tem como base a predominância da atividade agroindustrial.

Os atuais modelos cooperativistas agroindustriais de gestão sofreram e sofrem inúmeras críticas, sobretudo no aspecto de sua aproximação com o modelo corporativo (CORADINI e FREDERICQ, 1982). Aspectos como governança corporativa, separação entre propriedade e decisão, estilos de gestão, entre outros fazem parte desse contexto (HARRIS, STEFANSON e FULTON, 1996; COOK, CHADDAD e ILIOPOULOS, 2004; BIALOSKORSKI NETO, 2012). Tal modelo demonstra, porém, de modo contundente, ano após ano, os amplos resultados positivos alcançados, firmando-se como um sistema sólido e contributivo ao desenvolvimento regional (BIALOSKORSKI NETO, 2012). Os ambientes nos quais o cooperativismo está inserido carecem de investigações científicas mais aprofundadas, tanto como fator influenciador, como fator influenciado pela presença de tais entidades.

Assim, a pesquisa tem como direção central atender ao seguinte questionamento: os ambientes institucionais e socioculturais influenciam a gestão cooperativa da C. Vale - Cooperativa Agroindustrial - comparativamente às unidades paranaenses e paraguaias? Com vistas a isso, o eixo norteador desta pesquisa está fundamentado em analisar as influências dos ambientes institucionais na perspectiva de North (1990) e socioculturais nas perspectivas de Cameron e Quinn (1998) e Grootaert et al. (2003) na gestão cooperativa, com base na proposta de ligação teórica desses temas. A partir do estudo de caso da segunda maior cooperativa singular agroindustrial brasileira (OCB, 2014), a C. Vale, será possível observar tal objetivo, tendo em vista a predominância da sociedade nos estados do Paraná, Santa Catarina, Mato Grosso, Mato Grosso do Sul e na sua pioneira instalação no Paraguai, ultrapassando as fronteiras nacionais. Para fins comparativos da presença ou não de tais influências, serão analisa- 
das algumas unidades paranaenses e as unidades paraguaias devido à representatividade da amostra, bem como a possibilidade de ocorrerem agrupamentos (clusters) entre as mesmas.

De modo sintético, o estudo estabelece duas hipóteses centrais passíveis de teste para aceitação ou rejeição: H1) As unidades cooperativas inseridas no estado do Paraná, Brasil, possuem gestão heterogênea influenciada pelas regras formais e informais, bem como uma cultura interna voltada para o agrupamento e práticas que atendam a geração de capital social no ambiente em que estão inseridas. H2) As unidades cooperativas inseridas no Paraguai possuem gestão homogênea influenciada apenas pelas regras formais, bem como uma cultura interna voltada para a hierarquia da própria entidade e práticas que atendam à geração de capital social no ambiente no qual estão inseridas.

$\mathrm{Na}$ análise do primeiro ambiente, o institucional, o eixo central baseia-se no contexto econômico pautado na Nova Economia Institucional ${ }^{4}$, a qual foi definida por North (1990) a partir de regras sociais ou de interação humana. As instituições são responsáveis pelas regras formais, limitações informais e mecanismos de eficácia dos dois tipos de formas, ou seja, constituem a base imposta pelo ser humano para o relacionamento entre si (NORTH, 1990). Desse modo, as cooperativas podem ser observadas como instituições norteadoras da relação entre seus participantes, a partir da inserção de regras formais e informais com foco na sustentação da economia gerada por tal interação, assim como terem influências diretas ou indiretas do ambiente institucional em que estão inseridas.

As influências do segundo ambiente, o sociocultural, são contempladas a partir de duas perspectivas principais: a presença de características de gestão voltadas à geração do capital social e a caracterização da cultura da própria organização. O conceito de capital social, difundido por Putnam (2007), elevou a exploração do tema

4. Corrente de pensamento econômico estruturada por vários autores que serão explorados e discutidos ao longo do trabalho. a partir de seus estudos sobre as comunidades italianas. Para o autor, o capital social parte de características específicas voltadas às organizações sociais que podem ser relacionadas, tais como confiança, normas e sistemas que facilitam as ações coordenadas e a eficiência de uma sociedade.

Com base na relevância do tema ao longo dos anos, o Banco Mundial (BM) criou, em meados de 2003, um grupo temático de estudos sobre o capital social. Grootaert et al. (2003) desenvolveram um instrumento de mensuração do capital social, denominado Integrated Questionnaire for the Measurement of Social Capital (SC-IQ) $)^{5}$. O ponto de partida toma como foco os reflexos das cooperativas no modo de vida e nas relações sociais provenientes dessa atividade, desde que estas características sejam contempladas pela gestão de tais entidades. Porém, no contexto do estudo, destaca-se que o SC-IQ não visou analisar de modo específico o capital social nas cooperativas, mas os reflexos da gestão da cooperativa pesquisada nas características de geração desse capital.

$\mathrm{Na}$ perspectiva de caracterização de cultura organizacional, autores como Schein (1992) e Cameron e Quinn (1998) evidenciam modelos específicos para tais abordagens. Cameron e Quinn (1998) criaram o Competing Value Model (CVM), cujo objetivo se concentra na caracterização cultural de uma organização com base em um diagnóstico que reflete o modo grupal, hierárquico, inovador ou voltado ao mercado. Para tanto, a teoria e o modelo criado pelos autores viabiliza analisar se a organização possui foco interno e integração, foco externo e diferenciação, flexibilidade e liberdade ou, por fim, estabilidade e controle, possibilitando, assim, verificar se as influências dos ambientes culturais externos estão inseridas em uma entidade.

A pesquisa com cooperativas e suas respectivas atividades transfronteiriças ${ }^{6}$ é de caráter

5. Questionário Integrado para Medir Capital Social (QI-MCS).

6. O conceito transfronteiriço é aqui empregado para indicar que a ação dos agentes cooperativos e dos cooperados transcende o marco político da fronteira enquanto divisão territorial. 
inédito nas investigações científicas relacionadas ao tema. Begnis, Arend e Estivalete (2014) realizaram estudo específico sobre o agronegócio e identificaram pouca produção sobre o tema, com abordagens predominantemente econômicas. Diversos estudos abordam especificamente a discussão institucional, social e cultural das cooperativas ao redor do mundo 7 . A junção das três abordagens também configura o aprofundamento e o ineditismo do estudo, tendo em vista contemplar as principais influências predominantes à gestão cooperativista.

Apesar da delimitação junto à cooperativa, objeto do estudo, a contribuição das conclusões ao cooperativismo agroindustrial foi viabilizada, pela similaridade do modelo organizacional adotado por estas entidades e a atual predominância das práticas de gestão corporativa do modelo cooperativo nacional estabelecido por algumas cooperativas, principalmente as de grande porte estabelecidas na região Sul do Brasil. Conforme mencionado, tal possibilidade se pauta em diversos estudos que debatem essa nova geração estrutural das cooperativas (HARRIS, STEFANSON e FULTON, 1996; COOK, CHADDAD e ILIOPOULOS, 2004; BIALOSKORSKI NETO, 2012). Ressalta-se, porém, que o estudo não generaliza as cooperativas agroindustriais brasileiras em virtude de aspectos regionais e econômicos particulares a cada contexto.

\section{Fundamentação teórica}

Para atender a proposta da pesquisa, fez-se necessário o aprofundamento nas literaturas existentes sobre as temáticas investigadas. Assim, o referencial está contemplado em três discussões principais: o cooperativismo, o ambiente institucional e o ambiente sociocultural.

7. Os estudos considerados mais relevantes ao contexto da pesquisa foram explorados na fundamentação teórica.

\subsection{Cooperativismo}

A temática do cooperativismo é tomada de diferentes abordagens que focam as principais discussões na sua inserção no contexto econômico e social. Em virtude de parte das cooperativas atualmente utilizarem um modelo de gestão baseado no mercado competitivo nacional e internacional, muitas das atuais abordagens dão ênfase ao aspecto econômico. Os efeitos e as repercussões das ações cooperativas sobre as relações sociais e culturais dos agentes cooperativos requerem investigação científica para verificar as possíveis influências dessas relações na própria gestão cooperativista.

Os mais diferentes conceitos relacionados ao cooperativismo foram produzidos ao longo da história. Até alterações doutrinárias podem ser observadas. De acordo com Schallenberger (2003), o cooperativismo é mais bem definido a partir de uma doutrina econômica, em que o foco é sustentar a associação livre e autônoma de pessoas, cujos interesses são comuns, com característica solidária a atingir as necessidades de cada um e as coletivas. Ainda segundo o autor, as cooperativas são consideradas um sistema de organização socioeconômica, fundamentado nos sete princípios apresentados pela ICA (SCHALLENBERGER, 2003).

Costa (2010) sintetiza, a partir de ideias principais de autores como Sexton e Staatz, o cooperativismo agrícola, afirmando que são "organizações econômicas de propriedade coletiva, criadas pelos produtores rurais para fazer frente às falhas de mercado, pois as características dos mercados agrícolas propiciam possibilidades às empresas de extraírem sua renda". Face à representatividade e à predominância da atividade agrícola no Brasil, destaca-se que as cooperativas nacionais são constituídas, em sua maioria, pela cooperação de produtores rurais.

Com base nas discussões sobre o direito de propriedade e a participação nas cooperativas na década de 1990, denominou-se de Nova Geração de Cooperativas (NGC) a tendência a um modelo moderno e profissionalizado de gestão dessa 
atividade (HARRIS, STEFANSON e FULTON, 1996). Para Bialoskorski Neto (2012), esse novo modelo é definido "[...] como uma forma organizacional que mantém os princípios doutrinários do cooperativismo, mas que edifica uma nova arquitetura organizacional, que traz modificações nos direitos de propriedade e induz a organização cooperativa a um nível maior de eficiência econômica" (p. 116). O foco é dado, segundo Bialoskorski Neto (2012), à agregação de valor às commodities que são produzidas pelos agricultores e comercializadas pela cooperativa à qual estão associados, além da possibilidade de transferência das quotas de participação e do direito de entrega por parte dos mesmos associados.

As variadas abordagens de diferentes autores de âmbito nacional e internacional inserem as cooperativas com uma importante representação institucional, com o objetivo central de geração de benefícios e bem-estar cooperativo. Porém, desde as primeiras formalizações cooperativistas, ainda no século XIX, contínuas são as necessidades de uma melhor compreensão da evolução da atividade e as respectivas transformações sofridas por essa ao longo do tempo (SCHALLENBERGER, 2003).

\subsection{Ambiente institucional}

De acordo com o foco do estudo já apresentado, o primeiro ambiente externo a ser abordado, passível de influência ao processo de gestão cooperativa, é o institucional. Para tanto, o contexto utilizado tem como abrangência a Teoria Institucional na perspectiva da Nova Economia Institucional (NEI) pautada em seu aspecto econômico, a partir da definição das instituições como reguladoras de um ambiente, dada por Douglass North na década de 1990. A Teoria Institucional, desde a sua formalização, passou por diferentes transformações no modo como é abordada e utilizada nos estudos científicos. A moderna Teoria Institucional tem como ponto de partida as ideias de Berger e Luckman (1967), voltadas à importância dos agentes sociais no processo de criação de regras que regem uma sociedade e à respectiva interação gerada por meio de tais regras, normas e valores. Quando esses agentes passam a utilizar e assimilar essas regras e ações de modo constante dentro de um mesmo ambiente, esse processo é denominado de institucionalização (SCOTT e MEYER, 1991).

As definições concretas de instituições e organizações também são relevantes para a compreensão da melhora do desempenho econômico com base nas mudanças e inovações institucionais. "As instituições compreendem regras formais, limitações informais [...] e os mecanismos responsáveis pela eficácia desses dois tipos de normas. Em suma, constituem o arcabouço imposto pelo ser humano a seu relacionamento com os outros" (NORTH, 1994, p. 13). O autor define ainda que se as instituições são as regras do jogo e as organizações são os jogadores. "As organizações compõem-se de grupos de indivíduos dedicados a alguma atividade executada com determinado fim" (NORTH, 1994, p. 13).

North (1990) define que não há um modelo institucional perfeito. No entanto, há como se projetar o que seria considerado modelo ideal. Nesse aspecto, o autor afirma que não deveria haver restrições quanto à criação de instituições responsáveis pelo crescimento de oportunidades para as organizações. Em relação aos custos de transação, o processamento de informações seria uma opção interessante no que diz respeito à redução desses custos em um ambiente institucional.

Por fim, toda a abordagem de North (1990, 1994) em relação à Nova Economia Institucional insere a relevância das instituições e organizações no processo de inovação para haver desenvolvimento. Assim, se considerados os aspectos dos agentes inseridos no ambiente institucional a partir de suas decisões racionais limitadas, todas as características internas relacionadas, bem como os aspectos externos que influenciam as mudanças necessárias, a melhor performance econômica refletiria em melhores resultados e desenvolvimento social, com base na relevância das instituições e organizações. 


\subsection{Ambiente sociocultural}

A presente seção discute o ambiente sociocultural voltado ao contexto da pesquisa, ou seja, a partir de duas abordagens principais: a cultura organizacional e o capital social. Tais ideias formam a base conceitual necessária para atingir os objetivos propostos no estudo. Como o foco do trabalho é voltado à identificação e à análise das influências ambientais socioculturais no processo de gestão da cooperativa em questão, optou-se pela adoção dos conceitos de cultura organizacional refletida na entidade, bem como a existência de características de que tal processo gerencial tenha reflexos de geração de capital social.

\subsubsection{Cultura organizacional}

Com trabalhos notórios direcionados aos estudos culturais nas empresas desde a década de 1970, destaca-se Edgar H. Schein (1992), que aborda os conceitos de cultura organizacional, suas dimensões, interpretações e evolução. Para Schein (1992), a cultura ajuda e "ilumina" a situação da organização, buscando, nos aspectos relacionados ao comportamento individual e coletivo, as respostas sobre as influências culturais existentes. Hofstede (1994) também se destacou nos estudos sobre a cultura organizacional, de modo mais específico, a partir de casos desenvolvidos ainda na década de 1970 em empresas com atuação internacional. Hofstede (1994) conseguiu identificar as principais predominâncias das características culturais em uma mesma empresa; porém, com atuação em diferentes países.

Recentemente, Minkov e Hofstede (2012) atualizaram o estudo sobre as dimensões de cultura organizacional. Comparando também organizações em seus diferentes países de atuação, os autores identificaram que, a partir do crescimento econômico predominante na China nos últimos anos, muitos países do Ocidente já apresentam características de cultura organizacional a partir de dimensões de valores semelhantes.
Existem inúmeros estudos voltados à análise da cultura das organizações. Alguns propõem modelos de diagnóstico ou caracterização dessa cultura por meio de levantamentos internos e relacionamento de variáveis pautadas nos elementos que influenciam o processo de gestão empresarial (SCHEIN, 1992; HOFSTEDE, 1994). Esse estudo tomou como base o Competing Value Model (CVM), denominado de Modelo dos Valores Competitivos (MVC) elaborado por Cameron e Quinn na década de 1990, devido a sua pontualidade e precisão na caracterização da cultura organizacional. Outro motivo notável da escolha é que, ao contrário de alguns modelos específicos para esse tipo de análise, o CVM não possui viés no momento das respostas dos indivíduos em virtude do modo com as questões são inseridas, elevando a confiabilidade nas informações prestadas.

O CVM parte do questionamento junto aos indivíduos da organização sobre seis dimensões que tendem a caracterizar a cultura interna: as características dominantes; a liderança organizacional; o gerenciamento de pessoas e equipes; os aspectos de união organizacional; as caraterísticas voltadas à estratégia e as características de sucesso da organização. Cada dimensão relacionada possui quatro características passíveis de atribuição de um score. Ao final, esses scores são calculados e demonstram em qual quadrante classificatório de cultura a organização está inserida.

\subsubsection{Capital social}

O capital social é uma temática abordada em diversas áreas científicas, como a economia, a sociologia e a política. Segundo pesquisa realizada por Akçomak (2011), a exploração do tema já ultrapassou até mesmo as áreas mensuradas e já podem ser encontrados diversos estudos também nas áreas de negócio e até mesmo nas áreas da saúde. Nos diversos contextos de aplicação, o capital social é observado como uma forma de desenvolvimento humano, partindo de características culturais como metodologia de agregação de valores. Desde o século XX, os principais 
conceitos do tema são explorados. De modo mais recente, podem ser destacados autores como: Bordieu (1980), Coleman (1988), Putnam (1995, 2007) e Fukuyama (2002).

Desenvolvido em 2003 pelo Banco Mundial, o Integrated Questionnaire for the Measurement of Social Capital (SC-IQ) ou Questionário Integrado para Medir Capital Social (QI-MCS) é uma ferramenta cujo objetivo é a tentativa de mensuração por dados qualitativos sobre as várias dimensões do capital social. De acordo com Grootaert et al. (2003), o documento foi desenvolvido pelo Grupo Temático sobre Capital Social e esteve sujeito a extensivas contribuições e críticas por parte de consultores externos.

O SC-IQ é composto por seis dimensões específicas: grupos e redes; confiança e solidariedade; ação coletiva e cooperação; informação e comunicação; coesão e inclusão social; autoridade a ação política. Para Grootaert et al. (2003), embora o capital social seja conceituado nos níveis micro, médio e macro, o SC-IQ concentra-se na medida ao nível micro.

No presente estudo, utilizou-se uma adaptação diretamente baseada no SC-IQ. Tal fato é justificado em virtude do próprio Grupo Temático afirmar sobre o questionário que nem todas as questões enumeradas podem ser úteis em todos os lugares, nem todas as enunciações de uma questão em particular podem ser apropriadas para todo contexto e várias questões de importância local podem ser acrescentadas (GROOTAERT et al., 2003).

\section{Metodologia}

Nesta seção é apresentada a metodologia utilizada no estudo quanto à natureza, área da ciência, objetivos, procedimentos, objeto e abordagem do problema. Por fim, são apresentados o delineamento da coleta de dados junto à cooperativa e o respectivo processo utilizado para as análises dos dados e construção das conclusões.

\subsection{Caracterização metodológica}

A pesquisa pode ser classificada como exploratória e explicativa. Exploratória pelo fato de abordar, a partir das temáticas voltadas ao cooperativismo, Teoria Institucional, cultura organizacional e capital social, a essência da exploração aprofundada das influências e relações entre tais assuntos. Explicativa por analisar e comprovar cientificamente os reflexos dos ambientes institucionais e socioculturais na gestão cooperativa. Dessa forma, a investigação voltada a uma sociedade pontual ocorreu via coleta e posterior interpretação de dados junto à C. Vale - Cooperativa Agroindustrial de forma comparativa às diferentes unidades que compõem a organização (COOPER e SCHINDLER, 2003; SEVERINO, 2007; GIL, 2009).

Tendo como base a classificação de Gil (2009), os procedimentos técnicos adotados nesta pesquisa foram o bibliográfico e o documental. $\mathrm{O}$ trabalho tem o caráter de um estudo de caso. Para Severino (2007), o caso escolhido para a investigação "deve ser significativo e bem representativo, de modo a ser apto a fundamentar uma generalização para situações análogas, autorizando inferências". No mesmo sentido, Yin (2010) afirma que o estudo de caso é utilizado nas mais diversificadas situações científicas como forma de contribuição ao conhecimento dos fenômenos individuais, grupais, organizacionais, sociais, políticos e relacionados. Gerring (2008) define o estudo de caso como um fenômeno espacial delimitado e observado como um simples acontecimento no tempo ou em algum período de tempo.

Assim, tendo em vista a abrangência da cooperativa em questão, bem como sua representatividade econômica e social no contexto nacional conforme abordado na introdução, as conclusões tendem a um direcionamento análogo em situações semelhantes (SEVERINO, 2007). Em relação à abordagem do problema, no processo de construção da pesquisa foi aplicada uma análise qualitativa com a utilização de ferramentas específicas para a proposta de agrupamentos de unidades cooperativas ao final das análises. 


\subsection{Coleta, análise e interpretação dos dados}

Além das abordagens metodológicas mencionadas, a característica do estudo é o empírico-analítico, concretizado por meio de coleta, observação e análise dos dados. Trata-se de uma pesquisa explicativa, uma vez que busca o nexo entre a fundamentação teórica e o levantamento de dados, criando conclusões científicas reais à proposta apresentada. Apesar de a cooperativa abranger 106 unidades, o foco do estudo está voltado para uma análise entre as unidades mais representativas do estado do Paraná comparativamente às unidades paraguaias da organização.

Assim, por meio de amostragem não probabilística intencional por julgamento, os dados coletados foram suficientes para se chegar às conclusões necessárias ao objetivo geral proposto (COOPER e SCHINDLER, 2003). Essa técnica de amostragem permite ao pesquisador a liberdade na escolha dos participantes. Logo, por meio de discussão com os gestores da C.Vale, chegou-se às unidades mais representativas em termos históricos, sociais e econômicos contempladas no estado do Paraná, úteis para a finalidade do estudo, conforme exposto no Quadro 1.

\subsubsection{Análise do ambiente institucional: abordagem baseada em North}

Como forma de analisar as influências externas do ambiente institucional na gestão cooperativa, tomou-se como base a contextualização histórico-conceitual da Nova Economia Institucional com foco nas ideias de North (1990). Para fins de observar se tais influências existem efetivamente e quais seriam elas, o estudo teve como base metodológica de levantamento do ambiente institucional as entrevistas in loco com os gestores de cada unidade contemplada na pesquisa.

Como North (1994) define as instituições como a 'regra do jogo' em uma sociedade, foram contempladas nas entrevistas questões com o direcionamento sobre as influências ou não dessas instituições, formais ou informais, nas regiões contempladas pelas unidades cooperativas. As questões utilizadas na condução das entrevistas junto aos gestores tomaram como base as características teóricas, práticas e estruturais. Assim, as questões apresentadas aos gestores das unidades cooperativas possibilitaram analisar diretamente as influências do ambiente institucional no processo de gestão a partir dos conceitos previa-

Quadro 1. Amostra das unidades da pesquisa

\begin{tabular}{|l|l|l|l|l|}
\hline \multicolumn{1}{|c|}{ Unidade } & \multicolumn{1}{c|}{ Cidade } & \multicolumn{1}{c|}{ Estado } & \multicolumn{1}{c|}{ Mesorregião } \\
\hline Administração Central & Palotina & Paraná & Oeste & Brasil \\
\hline Campina da Lagoa & Campina da Lagoa & Paraná & Centro-Ocidental & Brasil \\
\hline Campo Mourão & Campo Mourão & Paraná & Centro-Ocidental & Brasil \\
\hline Floresta & Floresta & Paraná & Norte Central & Brasil \\
\hline Guarapuava & Guarapuava & Paraná & Centro-Sul & Brasil \\
\hline Mamborê & Mamborê & Paraná & Centro-Ocidental & Brasil \\
\hline Maripá & Maripá & Paraná & Oeste & Brasil \\
\hline Palotina & Palotina & Paraná & Oeste & Brasil \\
\hline São João do Ivaí & São João do Ivaí & Paraná & Norte Central & Brasil \\
\hline São Jorge do Ivaí & São Jorge do Ivaí & Paraná & Norte Central & Brasil \\
\hline Terra Roxa & Terra Roxa & Paraná & Oeste & Brasil \\
\hline Katuete & Katuete & Canindeyú & Noroeste Oriental & Paraguai \\
\hline Paloma & La Paloma Del Espiritu Santo & Canindeyú & Noroeste Oriental & Paraguai \\
\hline Cruce Guarani & Corpus Christi & Canindeyú & Noroeste Oriental & Paraguai \\
\hline
\end{tabular}

Fonte: Dados da pesquisa (2014). 
mente avaliados na Nova Economia Institucional (NEI), discutida por North (1990).

As entrevistas foram realizadas in loco nas cidades de Campina da Lagoa, Campo Mourão, Floresta, Guarapuava, Mamborê, Maripa, Palotina, São João do Ivaí, São Jorge do Ivaí, Terra Roxa, Katuetê, La Paloma Del Espiritu Santo e Corpus Christi com cada um dos gestores responsáveis pelas unidades da C. Vale, conforme roteiro elaborado previamente. $\mathrm{O}$ instrumento de coleta de dados utilizado foi composto por 10 (dez) questões abertas, bem como a abertura para demais discussões conduzidas durante cada entrevista. De acordo com as questões elaboradas para a entrevista, optou-se pelas perguntas abertas devido ao fato de as respostas serem livres. Ressalta-se também que as mesmas evitaram o viés de resposta elevando as características qualitativas para as posterio- res análises. O Quadro 2 alinha as questões com as respectivas abordagens teóricas utilizadas no referencial.

Após a condução das respectivas entrevistas junto aos gestores das unidades, para fins de interpretação dos dados coletados, o instrumento utilizado foi a análise de conteúdo. Para Campos (2013), a análise de conteúdo "vem se caracterizando atualmente como mais um instrumento metodológico para a compreensão dos diversos discursos do ser humano" (p. 265). O autor afirma ainda que analisar o conteúdo de uma entrevista exige do pesquisador " $[. .$.$] a com-$ preensão de que as palavras têm muito mais a dizer do que dizem. Não se trata de adivinhar, [...], mas sim de ver no conteúdo apresentado ao pesquisador o que de fato o fenômeno observado apresenta, tornando visível o oculto" (CAMPOS, 2013, p. 265).

Quadro 2. Relação das questões com o ambiente institucional de North

\begin{tabular}{|c|c|}
\hline Questões & Abordagem institucional de Douglass North \\
\hline $\begin{array}{l}\text { Q1. Quais motivos direcionaram a instalação da unidade coope- } \\
\text { rativa no município? }\end{array}$ & $\begin{array}{l}\text { Instalação da unidade cooperativa no município como forma } \\
\text { de redução da incerteza e, consequentemente, dos custos de } \\
\text { transação pelos agentes. }\end{array}$ \\
\hline $\begin{array}{l}\text { Q2. Quais as características socioculturais do município no qual } \\
\text { a cooperativa está inserida? }\end{array}$ & $\begin{array}{l}\text { Discussão sobre o desenvolvimento institucional a partir do } \\
\text { desenvolvimento histórico. }\end{array}$ \\
\hline $\begin{array}{l}\text { Q3. Qual a relação entre a cooperativa e demais instituições for- } \\
\text { mais e informais? }\end{array}$ & $\begin{array}{l}\text { Relação da cooperativa com instituições responsáveis pelas } \\
\text { legislações e regras formais e demais instituições informais } \\
\text { formadas pela própria sociedade. }\end{array}$ \\
\hline $\begin{array}{l}\text { Q4. O sistema político regional influencia ou é influenciado pela } \\
\text { cooperativa? }\end{array}$ & $\begin{array}{l}\text { Possibilita analisar se a cooperativa em um ambiente especí- } \\
\text { fico é uma instituição capaz de alterar as 'regras do jogo' ou } \\
\text { uma organização responsável pela dinâmica institucional. }\end{array}$ \\
\hline $\begin{array}{l}\text { Q5. Qual a participação dos produtores rurais do município jun- } \\
\text { to à cooperativa? }\end{array}$ & $\begin{array}{l}\text { Demonstra a representatividade da cooperativa como institui- } \\
\text { ção ou organização para a atividade agroindustrial no ambien- } \\
\text { te onde se insere. }\end{array}$ \\
\hline $\begin{array}{l}\text { Q6. Quais os motivos de escolha da cooperativa pelos produto- } \\
\text { res rurais? }\end{array}$ & $\begin{array}{l}\text { Relação de confiança entre agentes das transações para redu- } \\
\text { ção das incertezas. }\end{array}$ \\
\hline $\begin{array}{l}\text { Q7. Qual o nível de receptividade de novos modelos ou novas } \\
\text { tecnologias pelos cooperados? }\end{array}$ & $\begin{array}{l}\text { Caracterização geral dos agentes participantes do ambiente } \\
\text { institucional. }\end{array}$ \\
\hline $\begin{array}{l}\text { Q8. Os cooperados sugerem mudanças nos processos da coo- } \\
\text { perativa? }\end{array}$ & Características de mudança institucional. \\
\hline $\begin{array}{l}\text { Q9. As características econômicas locais influenciam nas deci- } \\
\text { sões cotidianas da cooperativa? }\end{array}$ & Mudança a partir das características institucionais. \\
\hline $\begin{array}{l}\text { Q10. A cooperativa é um agente gerador de capital econômico } \\
\text { para a região? }\end{array}$ & $\begin{array}{l}\text { Melhora da performance econômica com base nas mudanças } \\
\text { institucionais. }\end{array}$ \\
\hline
\end{tabular}

Fonte: Elaborado pelos autores com base em North (1990). 


\subsubsection{Análise do ambiente cultural: o Competing Value Model}

Conforme abordado no referencial teórico, para a presente pesquisa foi desenvolvida adaptação do Competing Value Model com a finalidade de identificar a cultura organizacional predominante nas unidades da cooperativa, de acordo com as caracterizações mencionadas sobre o modelo. As questões basearam-se no modelo de Cameron e Quinn (1998) e tiveram como finalidade a caracterização dos tipos de cultura organizacional, por meio das dimensões de Características Dominantes, Liderança Organizacional, Gerenciamento de Pessoas e Equipe, União Organizacional, Ênfase Estratégica e Critérios de Sucesso. Foram destacadas por meio de escala para que o respondente pudesse identificar as características atuais em relação à cultura da empresa.

O questionário foi desenvolvido por meio eletrônico e enviado aos respondentes para preenchimento online, ou seja, aos mesmos participantes de cada unidade entrevistados no processo de coleta de dados da análise do ambiente institucional. Foi utilizado o sistema SurveyMonkey ${ }^{\oplus \text {, }}$ que permite a elaboração de questões em diferentes formatos e criação de um link específico para que os participantes respondam diretamente os questionamentos, sendo que as respectivas respostas migram para uma base de dados específica acessada apenas pelo pesquisador. O questionário online foi separado em Parte I e Parte II.

A Parte I do questionário online foi estruturada conforme o modelo de Cameron e Quinn (1998), mencionado para fins de caracterização da cultura organizacional da unidade cooperativa correspondente. Essa parte relacionou 6 (seis) questões diretamente voltadas ao modelo com foco na análise dos 6 (seis) aspectos culturais mencionados. Os questionamentos direcionaram-se a identificar quais as características dominantes (ligadas a aspectos de pessoalidade), características de liderança (ligada ao estilo de liderança), características de gerenciamento de pessoas e

8. Copyright ( 1999-2014 SurveyMonkey. equipe (ligada a aspectos de gestão pessoal), características de união organizacional (ligadas a aspectos de individualismo), características de estratégia (ligada a fatores de competitividade) e, por fim, características de sucesso (ligadas a aspectos que fazem a organização bem-sucedida) que mais se aproximavam da realidade da unidade cooperativa.

Cada uma das 6 (seis) questões compreendia 4 (quatro) possibilidades de respostas sendo que, para cada uma, a atribuição de uma escala de 1 (um - pouco se aproxima) a 4 (quatro - muito se aproxima) foi permitida. As análises de cada resposta da Parte I serão abordadas no Capítulo 4, conforme o modelo teórico de análise da cultura organizacional proposto, bem como o questionário podem ser observados com detalhamentos no Apêndice A.

Após as respostas estabelecidas nos questionários, a tabulação geral dos dados se deu pela utilização de médias percentuais em cada uma das seis dimensões, conforme propõe o modelo. A tipologia de cultura organizacional que mais se aproximar dos $100 \%$ é a específica da unidade contemplada. Porém, mesmo que haja uma tipologia específica, as demais características de cada cultura organizacional também podem ser identificadas para cada uma das seis dimensões. Ou seja, mesmo que a unidade cooperativa tenha uma cultura organizacional predominante, características de outras tipologias culturais também poderão ocorrer e serem destacadas para a análise dos dados gerais.

A Parte II do questionário online tratou especificamente sobre o perfil do respondente e a unidade contemplada pelo estudo. Foram elaboradas 4 (quatro) questões que solicitavam, de modo pontual, a respectiva unidade da cooperativa, a idade do respondente, a formação do mesmo e, por fim, a quantidade de tempo de vinculação à C. Vale.

\subsubsection{Análise do ambiente social: o QI-MCS}

Como terceira etapa metodológica de coleta de dados, tem-se o modelo utilizado para fins 
de análise das influências sociais pautadas nos conceitos de capital social abordados no segundo capítulo do estudo. Para caracterização de influências voltadas à geração e capital social na cooperativa, utilizou-se a adaptação do modelo desenvolvido por Grootaert et al. (2003). Essa adaptação permite mensurar dados qualitativos sobre as várias dimensões do capital social do modelo, ou seja: grupos e redes; confiança e solidariedade; ação coletiva e cooperação; informação e comunicação; coesão e inclusão social; autoridade, capacidade (empowered) e ação política, que são pautados pelo modelo.

Diante disso e acreditando ser possível verificar as características de capital social das unidades cooperativas com base nas entrevistas previamente realizadas, adaptaram-se as seis dimensões do QI-MSC. Como forma de evitar o viés nas respostas do modelo de análise de geração de capital social pela cooperativa, bem como para a adaptabilidade do QI-MCS, o preenchimento das questões não foi solicitado aos gestores das unidades cooperativas entrevistados. Com base nas entrevistas realizadas e coleta de dados documentais, foi possível realizar a aplicação do modelo por meio da própria pesquisa.

Foram apresentadas cinco afirmativas para cada dimensão, destacadas em uma escala do tipo Likert, com cinco pontos, partindo da identificação de cada item em níveis: muito baixo, baixo, regular, alto e muito alto. Cada nível tem a atribuição relacionada a cada característica de capital social presente na dimensão adaptada do modelo QI-MCS.

$\mathrm{Na}$ primeira dimensão, denominada como Grupos e Redes, o objetivo é verificar a diversificação e predominância da atividade na comunidade em que pertence, por meio da análise das adesões dos agricultores familiares da região junto à cooperativa, a atuação e relacionamento da cooperativa com seus cooperados, com outras associações/cooperativas na região, assim como a participação dos cooperados nas decisões da sociedade. A dimensão Confiança e Solidariedade objetiva a avaliação dos níveis de confiança mútua entre comunidade e cooperados em relação à cooperativa, dos cooperados em relação aos demais cooperados, de ajuda entre cooperados e comunidade na sua região, assim como de ajuda dos projetos da cooperativa em relação à comunidade.

A dimensão denominada de Ação Coletiva e Cooperação busca avaliar as ações coletivas sociais realizadas pela cooperativa, entre os cooperados e a comunidade externa, a participação dos cooperados nas ações coletivas em prol da cooperativa, na obtenção de resultados atingidos pela realização de tais ações para a comunidade. A dimensão Informação e Comunicação objetiva identificar características com indagações direcionadas as informações econômico-financeiras, socioculturais e políticas prestadas pela cooperativa à comunidade e aos cooperados, assim como a acessibilidade dos cooperados aos meios de comunicação utilizados.

Na dimensão Coesão e Inclusão, o objetivo é identificar as condições de interação entre os cooperados e a comunidade externa, socialização dos projetos da cooperativa junto à comunidade, inclusão social dos não cooperados e possíveis conflitos econômicos, sociais e culturais entre cooperados. Por fim, para a dimensão Autoridade, Capacidade (empowered) e Ação Política, o objetivo é identificar conexão existente entre as cooperativas e representantes de instituições públicas buscando entender a capacidade da cooperativa em criar oportunidades, negociar e buscar recursos com benefícios econômicos, sociais e culturais favorecidos pelo governo em relação às cooperativas.

Com base na análise de conteúdo das entrevistas, bem como os dados levantados relativos ao ambiente institucional e cultural, a adaptação do modelo possibilita o estabelecimento de médias pautadas pelos níveis atribuídos a cada característica presente nas seis dimensões. Logo, após as atribuições dos respectivos níveis, é possível identificar, para fins comparativos entre as unidades cooperativas, quais as características de capital social contempladas nas seis dimensões. 


\section{Análise e interpretação dos dados}

Após a fase de coleta e interpretação de dados, a proposta de agrupamentos das unidades cooperativas da C. Vale, investigadas cientificamente, tem por objetivo verificar se há características dos três ambientes analisados comuns entre elas. Essa ideia teve como suporte ferramental a utilização do software $\mathrm{NVIVO}^{\circledast}$ versão 10 , cujos procedimentos viabilizaram a identificação ou não de clusters específicos.

O processo de agrupamentos dividiu-se basicamente em cinco etapas. A primeira delas consistiu na tabulação dos dados coletados nos três ambientes de análise, de modo que, para o ambiente institucional foram relacionadas as respostas às dez questões propostas com embasamento teórico da Nova Economia Institucional de North (1990), para o ambiente cultural foram relacionadas as características das seis dimensões propostas pelo CVM de Cameron e Quinn (1998) e, por fim, para o ambiente social foram relacionadas as características das seis dimensões propostas no QI-MCS de Grootaert et al. (2003).

A segunda etapa foi a inserção dessas observações por unidade cooperativa analisada no software $\mathrm{NVIVO}^{\circledast}$ versão 10, por meio da exportação desses dados externos junto ao programa. Dessa forma, a terceira etapa se constituiu na exploração dos dados via Análise de Clusters. Para esse fim, o NVIVO ${ }^{\circledR}$ solicitou as fontes de pesquisa, que foram os dados unidade a unidade, em que os clusters foram analisados por similaridade de palavras. Em linhas gerais, o software buscou, nos respectivos dados estruturados para cada unidade cooperativa, a similaridade de respostas aos 22 itens das três dimensões mencionadas.

Para avaliação das similaridades de palavras, o NVIVO ${ }^{\circledR}$ atribuiu três opções de coeficientes métricos: coeficiente de Jaccard, coeficiente de correlação de Pearson e coeficiente de Sorensen. Segundo Pohlmann (2007, p. 337), esse tipo de medida "[...] permite especificar as medidas de distância a serem usadas no clustering." O coeficiente de Jaccard estabelece um índice de similaridade que varia entre 0 (menos similar) e 1 (mais similar), assim como o coeficiente de Sorensen. O coeficiente de correlação de Pearson estabelece um índice de similaridade que varia entre -1 (menos similar) e 1 (mais similar), que foi utilizado nas análises (HAIR JR. et al., 2005; POHLMANN, 2007).

Na quarta etapa, o modelo foi propriamente rodado, gerando um dendograma para a análise dos respectivos agrupamentos identificados. $\mathrm{O}$ dendograma refere-se à representação gráfica dos clusters, conforme a Figura 1. Para Hair Jr. et al. (2005), é uma "representação gráfica (gráfico em árvore) dos resultados de um procedimento hierárquico no qual cada objeto é colocado em um eixo e o outro eixo representa os passos no procedimento hierárquico" (p. 382). Hair Jr. et al. (2005) definem ainda objeto como "pessoa, produto ou serviço, empresa ou qualquer outra entidade que possa ser avaliada quanto a uma determinada quantidade de atributos" (p. 383). A quinta e última etapa se refere especificamente à interpretação do dendograma e dos respectivos clusters formados entre as unidades cooperativas.

Figura 1. Dendograma dos clusters

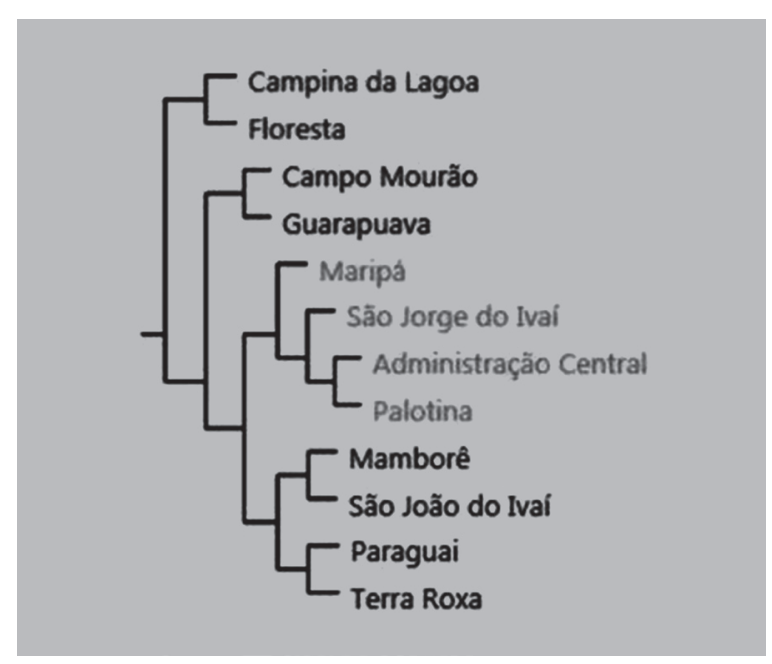

Fonte: Elaborada via $\mathrm{NVIVO}^{\oplus}$.

Com base no dendograma gerado pelo $\mathrm{NVIVO}^{\circledR}$, a partir das características institucionais, culturais e sociais das unidades cooperativas, foi possível identificar quatro clusters ou agrupamentos principais: 1) Unidades Campina 
da Lagoa e Floresta; 2) Unidades Campo Mourão e Guarapuava; 3) Unidades Maripá, São Jorge do Ivaí, Administração Central e Palotina; 4) Unidades Mamborê, São João do Ivaí, Paraguai e Terra Roxa. Inicialmente, observa-se que os aspectos territoriais ou geográficos não influenciaram nos agrupamentos via características institucionais, culturais e sociais. Para cada cluster existem, no mínimo, duas mesorregiões contempladas. Destaque para o terceiro agrupamento que reúne, ao mesmo tempo, unidades cooperativas contempladas em três mesorregióes mais o Paraguai.

\subsection{Agrupamento 1}

O primeiro agrupamento a ser analisado apresentou forte relação de características entre as unidades cooperativas da C. Vale de Campina da Lagoa, estabelecida na mesorregião Centro-Ocidental paranaense, e Floresta, estabelecida na mesorregião Norte-Central. Em relação às características contidas no ambiente institucional, observou-se que todas as sínteses das dez respostas geradas a partir das entrevistas com os gestores condicionaram à similaridade. $\mathrm{O}$ motivo de entrada da cooperativa nos municípios se deu em virtude da recondução da antiga Coopermibra. Em termos de características socioculturais, o desenvolvimento institucional da unidade cooperativa ocorre a partir do desenvolvimento histórico da região, ou seja, as características sociais e culturais da cooperativa são moldadas de acordo com os aspectos regionais do ambiente a qual está inserida. Já a relação entre a cooperativa e demais entidades formais e informais ocorre de modo moderado, ou seja, não há envolvimento aprofundado na relação. No contexto político de criação de regras, por exemplo, em ambos os municípios a cooperativa é uma organização do ambiente institucional, conforme North (1990), não se direcionando à 'criação' das mesmas, mas apenas participando conforme o contexto institucional regional.

A participação dos produtores rurais do município em relação à atividade agroindustrial da cooperativa ocorre de modo moderado.
O principal fator que condiciona a escolha da C. Vale pelos agricultores regionais é a migração da antiga cooperativa e crescente relação de confiança entre esses agentes como forma de redução de custos, aumento de ganhos e redução das incertezas. Porém, esses mesmos produtores possuem moderada receptividade a novos modelos ou novas tecnologias que surgem. Percebeu-se, também, uma baixa participação nos processos de mudança da cooperativa em ambas as unidades, quando esses ocorrem. As características econômicas dos municípios também pouco influenciam nas decisões cotidianas da cooperativa, tendo em vista que boa parte desse processo ocorre nas assembleias. Identificou-se também uma baixa relação entre geração de capital econômico via cooperativa e economia regional.

No ambiente cultural, ambas as unidades cooperativas tiveram tipologias de cultura organizacional identificadas como as de mercado. Nesse contexto, as unidades são orientadas aos resultados e à competitividade. A liderança contempla tais aspectos de orientação a resultado com estilo gerencial voltado a atingir objetivos previamente estabelecidos. Em termos de união organizacional, notam-se, mais uma vez, a ênfase nos resultados e a realização de metas.

As unidades cooperativas de Campina da Lagoa e Floresta também tiveram características de ambiente social semelhantes. Como o contexto de análise se deu a partir das dimensões de capital social identificadas em cada unidade junto às seis dimensões estabelecidas, em ambas as unidades tais características se apresentaram entre as formas regular e alta. A somatória dessas relações atribuiu um percentual de $76,67 \%$ para as duas unidades entre as escalas regulares e altas, conforme debatido previamente nas análises do ambiente social. As dimensões de confiança e solidariedade, ação coletiva e cooperação, e coesão e inclusão social foram as que mais se aproximaram.

Para finalizar as análises do agrupamento 1, o software $\mathrm{NVIVO}^{\circledR}$ disponibiliza uma tagcloud ${ }^{9}$,

9. Equivalente a uma "nuvem de palavras". 
cuja finalidade é relacionar as principais palavras que se repetem nos dados que foram avaliados em cada cluster.

Figura 2. Tagcloud do agrupamento 1

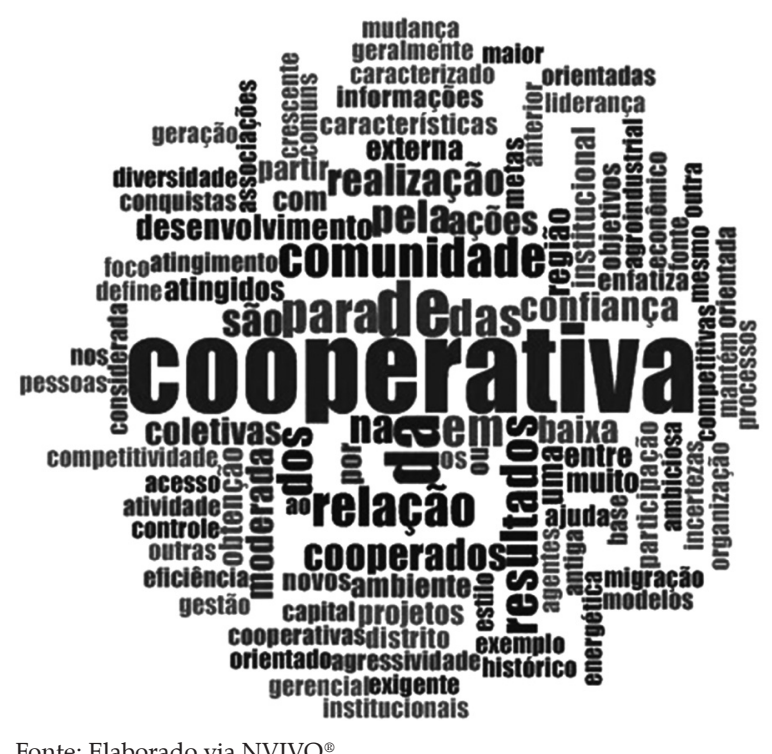

Fonte: Elaborado via $\mathrm{NVIVO}^{\circledast}$.

\subsection{Agrupamento 2}

$\mathrm{O}$ segundo agrupamento a ser analisado contemplou a unidade de Campo Mourão, estabelecida na mesorregião Centro-Ocidental paranaense, e a unidade de Guarapuava, estabelecida na mesorregião Centro-Sul do estado do Paraná. No contexto do ambiente institucional, as unidades de Campo Mourão e Guarapuava obtiveram algumas características que as agrupassem por meio das respostas estabelecidas nos questionamentos realizados aos gestores. A justificativa da entrada das unidades cooperativas nos dois municípios ocorreu em virtude da recondução da gestão da antiga Coopermibra. Dessa forma, as características socioculturais desses municípios influenciam diretamente do processo de gestão, tendo em vista que o desenvolvimento institucional das unidades cooperativas ocorre a partir do desenvolvimento histórico da região. A coo- perativa é uma organização inserida no ambiente institucional.

Há moderada participação dos produtores rurais do município nas atividades agroindustriais da cooperativa. A escolha da C. Vale pelos agricultores regionais é a migração da antiga Coopermibra e crescente relação de confiança como forma de redução de custos e redução das incertezas. Há baixa sugestão e participação nos processos de mudança da cooperativa por parte dos cooperados. Em ambas as unidades identificou-se uma baixa relação entre o crescimento econômico dos municípios e o crescimento econômico da cooperativa.

Nas análises do ambiente cultural, a unidade Campo Mourão obteve tipificação de cultura organizacional identificada simultaneamente como de mercado e como grupal. A unidade Guarapuava obteve a tipificação de cultura organizacional grupal estabelecida pelo questionário eletrônico aplicado e posteriormente analisado. Dessa forma, nota-se que as unidades se assemelham em termos de cultura organizacional grupal ou clã, ou seja, na tipificação em que as questões de relações humanas entre a própria cooperativa e os respectivos associados se moldam como as características familiares.

Dentre os três ambientes analisados para a formação do agrupamento, o ambiente social foi o que apresentou menor relação de características. Com base no modelo utilizado para identificar predominâncias de dimensões de capital social, a unidade Campo Mourão obteve média de $70 \%$ de características entre regular e forte. Já a unidade de Guarapuava obteve média de 56,67\% predominante entre baixas e regulares características de capital social. As dimensões que mais se aproximaram foram confiança e solidariedade, ação coletiva e cooperação e informação e comunicação. Assim como o primeiro cluster, o agrupamento 2 também teve uma tagcloud gerada conforme a Figura 3. 
Figura 3. Tagcloud do agrupamento 2

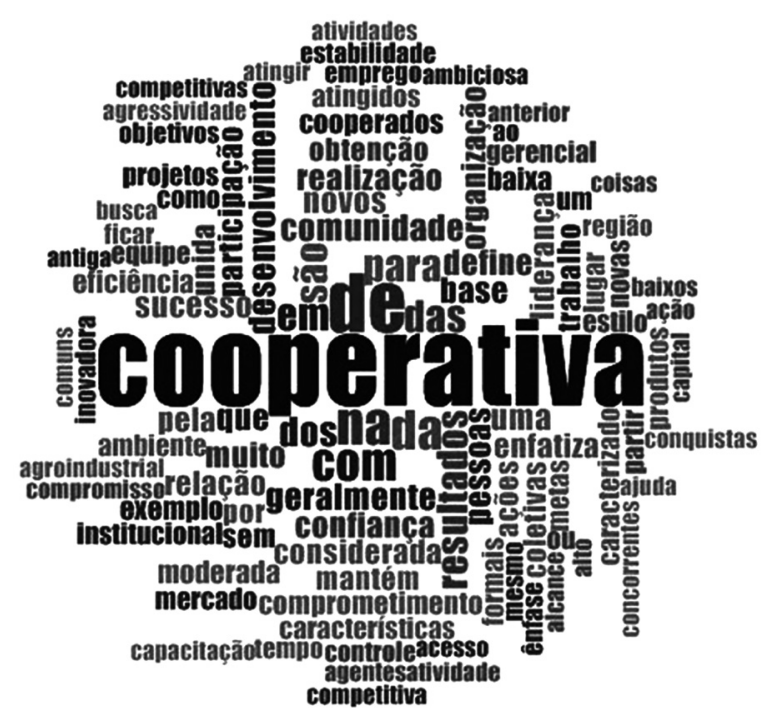

Fonte: Elaborada via NVIVO ${ }^{\oplus}$.

\subsection{Agrupamento 3}

O terceiro agrupamento gerado se constituiu das unidades de Maripá, Administração Central e Palotina, ambas estabelecidas na mesorregião Oeste do estado do Paraná, e da unidade de São Jorge do Ivaí, estabelecida na mesorregião Norte-Central paranaense. Apesar da criação do agrupamento com as quatro unidades cooperativas, $\mathrm{o}$ dendograma da Figura 4 demonstra uma ampla similaridade de características, como por exemplo, entre as unidades Administração Central e Palotina, gerando um novo cluster. Pelo modelo de análise do dendograma é possível afirmar que a unidade Maripá se agrupa com o conjunto formado pelas unidades São Jorge do Ivaí, Administração Central e Palotina. Dessa mesma forma, a unidade São Jorge do Ivaí se agrupa com o cluster formado pelas unidades Administração Central e Palotina, os quais geram um novo cluster.

Isso se explica pela forma como a Análise de Agrupamentos funciona a partir da relação de características entre os objetos de maneira hierárquica. Pohlmann (2007) afirma que "uma importante característica dos procedimentos hierárquicos é que os resultados de um estágio anterior são sempre incluídos dentro dos resultados dos estágios seguintes, de forma similar a uma árvore" (p. 345).
Ainda que exista a geração de mais de um cluster dentro do terceiro agrupamento, as análises de semelhanças de características foram realizadas de um modo geral entre as quatro unidades cooperativas contempladas no grupo. Para a quantidade de agrupamentos, Pohlmann (2007) afirma que "[...] o pesquisador deve complementar o julgamento estritamente empírico com quaisquer aspectos conceituais e teóricos acerca das relações estudadas que podem sugerir um número natural de grupos" (p. 352).

No primeiro ambiente da análise, o institucional, as quatro unidades cooperativas apresentaram várias características semelhantes. Nos municípios de Maripá, São Jorge do Ivaí e Palotina, a cooperativa C. Vale se destaca pela ampla participação em conjunto com demais entidades da sociedade e com instituições responsáveis pelas legislações e regras formais no que tange as relações institucionais. Dessa forma, as unidades cooperativas, ao contrário dos agrupamentos anteriores, são consideradas instituições capazes de influenciar diretamente o ambiente institucional.

Nos três municípios, os produtores rurais cooperados possuem alta participação na atividade agroindustrial do ambiente. Esse fator demonstra a representatividade da cooperativa no agronegócio das regiões. Uma característica evidente nas unidades de Maripá, São Jorge do Ivaí, Administração Geral e Palotina é a forte influência do ambiente econômico local no processo de gestão da cooperativa. Como há uma relação ampla entre o agronegócio e a cooperativa, esse ambiente econômico torna-se relevante às decisões. A última característica do ambiente institucional identificada é a alta geração de capital econômico pela cooperativa nesses municípios.

Um dos fatores que destaca a unidade de Maripá em um distanciamento maior das demais unidades relacionadas pelo cluster apresentado no dendograma é o ambiente cultural. Enquanto as unidades de São Jorge do Ivaí, Administração Central e Palotina obtiveram tipificação de cultura organizacional de mercado, a unidade de Maripá obteve a tipificação grupal ou clã. 
As unidades cooperativas com cultura organizacional de mercado possuem como características similares às seis dimensões de análise o foco voltado à obtenção de resultados, satisfação de mercado e competitividade. Já a cultura organizacional grupal ou clã, identificada na unidade Maripá, apesar de também ter relacionado características de gestão voltada aos resultados, estabelece a pessoalidade do ambiente, em que há forte predominância de trabalho em equipe, relações humanas e traços de gestão baseados em aspectos familiares.

Com base nas características de capital social, identificadas nas seis dimensões propostas pelo modelo, o ambiente social das unidades cooperativas do terceiro agrupamento também obteve similaridades destacáveis. A unidade Maripá obteve média de $86,67 \%$ de características de capital social estabelecidas entre regulares, altas e muito altas. São Jorge do Ivaí obteve média de 76,67\% de predominância de características entre regular a alta. A unidade Administração Central com média de $76,67 \%$ e Palotina com média de $80 \%$ estabeleceram predominância de características de capital social entre alta e muito alta, o que reforça os agrupamentos gerados demonstrados no dendograma. A Figura 4 relaciona as palavras que mais se repetiram nas análises conforme a tagcloud gerada.

Figura 4. Tagcloud do agrupamento 3

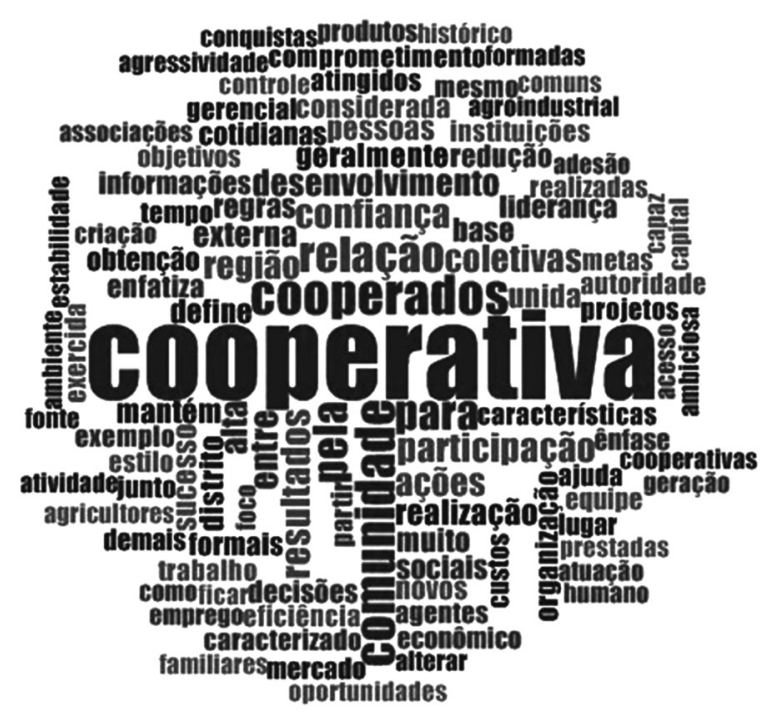

Fonte: Elaborado via NVIVO ${ }^{\circledR}$.

\subsection{Agrupamento 4}

O quarto e último agrupamento estabelecido pelas análises se apresentou como o mais heterogêneo em termos de localização territorial e geográfica entre as unidades contempladas. A unidade Mamborê está inserida na mesorregião Centro-Ocidental paranaense, a unidade São João do Ivaí está inserida na mesorregião Norte-Central paranaense, a unidade Terra Roxa se insere na mesorregião Oeste do estado do Paraná e, por fim, as unidades Katuete, Paloma e Cruce Guarani estão inseridas no Departamento de Canindeyú, Paraguai, ultrapassando as fronteiras brasileiras.

Assim como o agrupamento anteriormente explorado, o quarto agrupamento apresentou outros dois clusters formados pelas unidades Mamborê-São João do Ivaí e Paraguai-Terra Roxa. Para fins de análise, foram utilizados os mesmos critérios anteriormente discutidos sobre a quantidade de agrupamentos e as explorações gerais. No que tange ao ambiente institucional, houve características semelhantes às quatro regiões contempladas no quarto agrupamento.

Em relação às características socioculturais das quatro regiões, destaca-se o desenvolvimento institucional das unidades cooperativas, o qual está baseado a partir do próprio desenvolvimento histórico das respectivas regiões. Assim, as análises demonstraram que, para as seis unidades anteriormente mencionadas, a cooperativa é uma organização inserida no ambiente institucional das quatro regiões. Porém, mesmo caracterizada como uma organização e não como uma instituição, as unidades cooperativas possuem forte participação em conjunto com demais entidades formais e informais das específicas sociedades no que tange ao estabelecimento de legislações e demais regras presentes na dinâmica institucional dos municípios.

Nas análises do ambiente cultural, foi possível identificar diferentes tipificações de cultura organizacional. A unidade Mamborê apresentou cultura organizacional predominante nas tipologias grupal e hierárquica. As unidades São João do Ivaí e Terra Roxa apresentaram tipologia de cultura organizacional de mercado. Já as unida- 
des paraguaias apresentaram tipologia de cultura organizacional hierárquica. Em linhas gerais, o agrupamento apresenta características de gestão baseada na obtenção de resultados, na condução ordenada por meio de regras e burocracia, e nas relações humanas com traços familiares. A Figura 5 esboça a tagcloud do quarto agrupamento.

Figura 5. Tagcloud do agrupamento 4

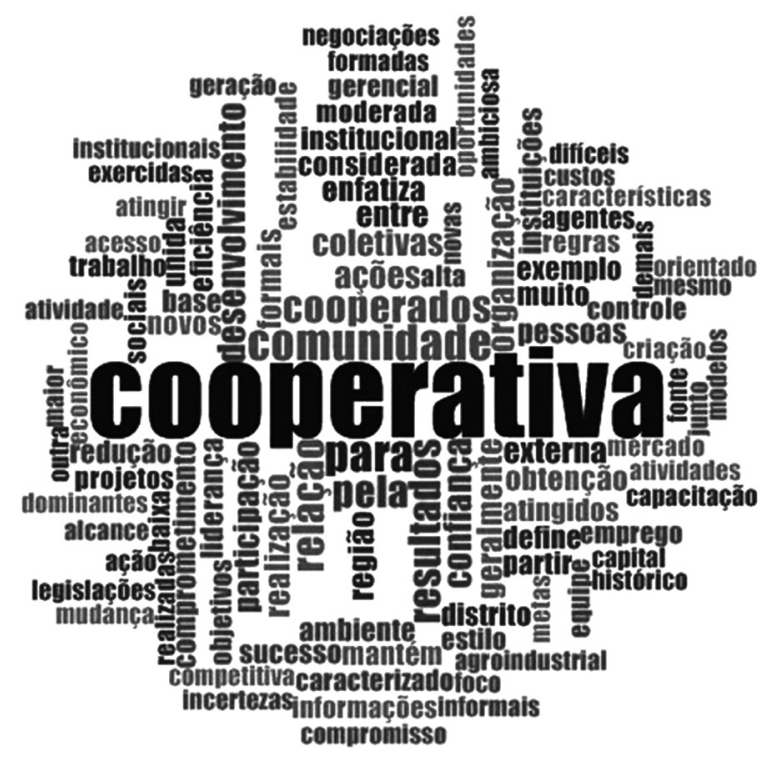

Fonte: Elaborado via NVIVO®

No contexto social, com base na atribuição de características de capital social compostas em seis dimensões estabelecidas no modelo utilizado, as unidades cooperativas também se assemelham em alguns aspectos. As unidades Mamborê e São João do Ivaí apresentam média de 73,33\% de características de capital social entre regular e alta. A unidade Terra Roxa apresenta média de 96,67\% entre regular e muito alta. Por fim, as unidades paraguaias apresentam média de $60 \%$ de características de capital social entre muito baixa e regular, o que demonstra pouca influência nesse contexto.

\section{Conclusões}

Em relação ao objetivo central da pesquisa, chegou-se à conclusão de que há influência dos ambientes institucionais e socioculturais na gestão da cooperativa, presentes nas unidades estudadas do estado do Paraná e do Paraguai, conforme a base teórica utilizada (NORTH, 1990; CAMERON e QUINN, 1998; GROOTAERT et al., 2003). Porém, de modo comparativo, não houve separação direta entre Brasil e Paraguai, tendo em vista que as unidades paraguaias apresentaram características institucionais e socioculturais que as assemelharam a determinadas unidades paranaenses. Assim, foi possível observar que mesmo a C. Vale sendo uma única cooperativa inserida nas regiões contempladas, os ambientes institucionais e socioculturais fazem com que os processos de gestão se adaptem às características dos respectivos ambientes, demonstrando o transfronteirismo dos mesmos.

Dessa maneira, quanto ao problema de pesquisa estabelecido na introdução do estudo, sobre se os ambientes institucionais e socioculturais influenciarem a gestão cooperativa da C. Vale Cooperativa Agroindustrial comparativamente às unidades paranaenses e paraguaias pôde-se concluir que a resposta é afirmativa. No entanto, foi possível identificar que as unidades paranaenses não apresentaram heterogeneidade em relação às influências estabelecidas pelas teorias propostas na fundamentação. As análises comprovaram que a questão geográfica ou territorial não influenciou na semelhança de características ambientais, sendo que estas foram corroboradas, tendo em vista a criação de agrupamentos específicos de unidades cooperativas instaladas em diferentes regiões.

Em uma análise mais específica, foram criados quatro agrupamentos contemplando unidades cooperativas de diferentes regiões, cujas características de influências dos três ambientes abordados na gestão se assemelharam. O primeiro agrupamento contemplou as unidades de Campina da Lagoa e Floresta. O segundo agrupamento contemplou as unidades de Campo Mourão e Guarapuava. O terceiro agrupamento, as unidades de Maripá, São Jorge do Ivaí, Administração Central e Palotina. O quarto e último agrupamento contemplou as unidades de Mamborê, São João do Ivaí, Terra Roxa e unidades do Paraguai. 
Diante das análises realizadas nas unidades cooperativas contempladas no estudo, foi possível avaliar a aceitação ou rejeição das duas hipóteses desenvolvidas na etapa introdutória do estudo: H1) as unidades cooperativas inseridas no estado do Paraná, Brasil, possuem uma gestão heterogênea influenciada pelas regras formais e informais, bem como uma cultura interna voltada para o agrupamento e a práticas que atendam à geração de capital social no ambiente no qual estão inseridas; H2) as unidades cooperativas inseridas no Paraguai possuem gestão influenciada apenas pelas regras formais, bem como uma cultura interna voltada pela hierarquia da própria entidade e práticas que atendam a geração de capital social no ambiente no qual estão inseridas.

A primeira hipótese pode ser considerada rejeitada em virtude de, conforme os próprios clusters criados, não existir heterogeneidade no processo de gestão, já que sofre influências dos ambientes institucionais e socioambientais; porém, com características amplamente diferentes. A característica de as unidades cooperativas de Palotina, Administração Central, Maripá e São Jorge do Ivaí serem as únicas consideradas instituições de acordo com a teoria de North (1990) já denota a rejeição da hipótese estabelecida.

A segunda hipótese, voltada às unidades paraguaias da C. Vale, também foi rejeitada devido a dois fatores preponderantes. Inicialmente não se pode afirmar que o processo de gestão dessas unidades seja homogêneo em virtude de elas terem sido agrupadas com outras unidades cooperativas brasileiras. Assim, pode-se afirmar também que a fronteira territorial ou política não influencia nesse processo. Por outro lado, apesar de a hipótese estabelecer corretamente uma cultura hierárquica voltada à formalidade de inserção em um ambiente estrangeiro, as práticas têm como foco a competitividade para a continuidade, com baixa atribuição de geração de capital social no ambiente em que estão inseridas.

Por fim, além do delimitado objetivo central de analisar as influências dos três ambientes nos processos de gestão das unidades, os objetivos específicos de compreender o processo de formação e constituição da C. Vale, analisar a gestão com base nas premissas da NEI, caracterizar as culturas organizacionais predominantes em cada unidade, mensurar as características de capital social das unidades e comparar tais práticas entre o Paraná e o Paraguai foram atingidos durante o processo cientifico. Além disso, o estudo construiu um embasamento institucional e sociocultural para a aplicabilidade em futuras pesquisas no tema cooperativista.

De acordo com o embasamento teórico sobre a Nova Geração de Cooperativas (NGC), conceituado como um modelo moderno e profissionalizado de gestão dessa atividade, a C. Vale, a partir das análises desenvolvidas, bastante se aproxima de tal modelo (HARRIS, STEFANSON e FULTON, 1996). Apesar dos princípios doutrinários do cooperativismo serem mantidos, há uma nova arquitetura organizacional, induzindo a C. Vale a um maior nível de eficiência econômica (BIALOSKORSKI NETO, 2012).

\section{Referências}

AKÇOMAK, S. Social capital of social capital researchers. Review of Economics and Instituitions, v. 2, n. 2, 2011.

BEGNIS, H. S. M., AREND, S. C. e ESTIVALETE, V. F. B. Em frente ao espelho: a produção do conhecimento em cooperativas na Revista de Economia e Sociologia Rural. Revista de Economia e Sociologia Rural, Piracicaba/ SP, v. 52, n. 1, p. 99-116, jan./mar. 2014.

BERGER, P. e LUCKMAN, T. The social construction of reality. New York: Doubleday, 1967.

BIALOSKORSKI NETO, S. Economia e gestão de organizações cooperativas. 2. ed. São Paulo: Atlas, 2012.

BOURDIEU, P. Le capital social. Actes de La recherche em sciences sociales, v. 31, jan. 1980.

CAMERON, K. S. e QUINN, R. E. Diagnosing and changing organizational culture: based on the competing values framework. Michigan: Addison-Wesley, 1998.

CAMPOS, D. C. de. A análise de conteúdo na pesquisa qualitativa. In: BAPTISTA, M. N. e CAMPOS, D. C. de. Metodologias de pesquisa em ciências: análises quantitativa e qualitativa. Rio de Janeiro: LTC, 2013. p. 265-288. 
COLEMAN, J. S. Capital in the creation of human capital. The American Journal of Sociology, v. 94, 1988.

COOK, M. L., CHADDAD, F. R. e ILIOPOULUS, C. Advances in cooperative theory since 1990: a review of agricultural economics literature. In: HENDRIKSE, G. W. J. Restructuring agricultural cooperatives. Erasmus University Rotterdam, 2004.

COOPER, D. R. e SCHINDLER, P. S. Métodos de pesquisa em administração. 7. ed. Porto Alegre: Bookman, 2003.

CORADINI, O. L. e FREDERICQ, A. Agricultura, cooperativas e multinacionais. Rio de Janeiro: Zahar Editores, 1982.

COSTA, D. R. M. Propriedade e decisões de gestão em organizações cooperativas agropecuárias brasileiras. Tese de Doutorado. EESP - FVG, São Paulo, 2010.

FUKUYAMA, F. Capital social. In: HUNTINGTON, S. P. e LAWRENCE, H. (Org.). Cultura importa: os valores que definem o progresso humano. Rio de Janeiro: Record, 2002.

GERRING, J. Case study research: principles and practices. New York: Cambridge University Press, 2008.

GIL, A. C. Como elaborar projetos de pesquisa. 4. ed. São Paulo: Atlas, 2009.

GROOTAERT, C. et al. Integrated Questionnaire for the Measurement of Social Capital (SC-IQ). Banco Mundial, GrupoTemáticosobre Capital Social. Washington DC, 2003.

HAIR JR., J. F. et al. Análise multivariada de dados. 5. ed. Porto Alegre: Bookman, 2005.

HARRIS, A., STEFANSON, B. e FULTON, M. New generation cooperatives and cooperative theory. Journal of Cooperatives, v. 11, p. 15-28, 2006.

HOFSTEDE, G. Culture and organizations: software of the mind, intercultural cooperation and its importance for survival. London: Harper Collins, 1994.
ICA - International Co-operative Alliance. Disponível em: <http://www.ica.coop>. Acesso em: 24 jun. 2014.

MINKOV, M. e HOFSTEDE, G. Hofstede's fifth dimension: new evidence from the world values survey. Journal of Cross-Cultural Psychology, v. 43, n. 1, p. 3-14, 2012.

NORTH, D. C. Institutions, institutional change and economic performance. New York: Cambridge University Press, 1990.

Custos de transação, instituições e desempenho econômico. Rio de Janeiro: Instituto Liberal, 1994.

OCB - Organização das Cooperativas Brasileiras. Relatório de Atividades OCB 2013, 2014. Disponível em: $<$ http:|www.ocb.org.br>. Acesso em: 3 set. 2014.

POHLMANN, M. C. Análise de conglomerados. In: CORRAR, L. J., PAULO, E. e DIAS FILHO, J. M. (Coord.). Análise multivariada: para cursos de administração, ciências contábeis e economia. São Paulo: Atlas, 2007.

PUTNAM, R. D. Comunidade e democracia: a experiência da Itália moderna. Rio de Janeiro: Editora FGV, 2007.

.Tuningin, tuning out: the strange disappearance of social capital in America. Political Science and Politics, v. 28, n. 4, p. 664-683, dez. 1995.

SCHALLENBERGER, E. Cooperativismo e desenvolvimento comunitário. Revista Mediações, Londrina, v. 8, n. 2, p. 9-26, jul./dez. 2003.

SCHEIN, E. H. Organizational culture and leader ship. 2. ed. San Francisco: Jossey-Bass Publishers, 1992.

SCOTT, W. R. e MEYER, J. W. The organizational of societal sectors. In: POWELL, W. W. e DIMAGGIO, P. J. The new institutionalism in organization analysis. Chicago: Universityof Chicago Press, 1991.

SEVERINO, A. J. Metodologia do trabalho científico. 23. ed. São Paulo: Cortez, 2007.

YIN, R. K. Estudo de caso: planejamento e métodos. 4. ed. Porto Alegre: Bookman, 2010. 
